\title{
ESTABLISHMENT OF HUMAN NEUROBLASTOMA CELL-LINE (SK-N-SH) AS AN in vitro MODEL OF MORPHINE ADDICTION
}

\author{
NOOR AZUIN SULIMAN ${ }^{1 *}$, NOOR AZLINA ABU BAKAR ${ }^{1}$, \\ MOHAMAD ARIS MOHD MOKLAS ${ }^{2}$ and CHE NORMA MAT TAIB ${ }^{2}$ \\ ${ }^{1}$ Faculty of Medicine and Health Science, Universiti Sultan Zainal Abidin (UniSZA), \\ Kampus Kota, Jalan Sultan Mahmud, 20400 Kuala Terengganu, Malaysia \\ ${ }^{2}$ Department of Biomedical Sciences, Faculty of Medicine and Health Sciences, \\ Universiti Putra Malaysia, 43400 UPM Serdang, Selangor, Malaysia \\ *E-mail:azuinsuliman@unisza.edu.my
}

Accepted 9 September 2021, Published online 30 November 2021

\begin{abstract}
The usage of morphine for analgesia purposes is widely known, usually for the post-operation procedure and as chronic pain management. However, addiction and overdose liabilities before morphine usage are also common. Morphine addiction is observed and studied from various perspectives; tolerance, dependence, and withdrawal. With growing and expending research field, researches on addiction were done using in vivo and in vitro model. However, the scientific evidence of morphine addiction using human neuroblastoma cell lines is uncommon. Thus, the present study was designed and conducted to observe the liability of SK-N-SH, as a model for morphine addiction. The cells were administrated with morphine for 24 $\mathrm{hr}$ before being treated with methadone. The cytosolic fraction of the cell was collected and used for determining the addiction mechanism. Data showed the involvement of the $\mu$-opioid receptor in expressing the addictive properties of morphine. Exposure to $24 \mathrm{hr}$ morphine had increased the protein level responsible for addiction and reduce the protein levels expressing the endocytic machinery, desensitization of receptors, and cellular adaptation. The altered proteins level was normalized by the treatment of methadone. The study proposed the use of SK-N-SH as an addiction model, as it showed morphine addiction and methadone anti-addiction properties.
\end{abstract}

Key words: Cellular adaptation, internalization, morphine addiction, withdrawal properties

\section{INTRODUCTION}

Morphine is the most potent analgesic used for chronic pain regardless of the limitation of the usage. It tends to initiate addiction, observed through tolerance, severe withdrawal symptoms, and rewarding properties. More studies were conducted and designed in various perspectives, from understanding the mechanism of the therapeutic uses of morphine (Yadlapalli et al., 2017), the stimulated-addiction mechanism (reviewed by Ahmad et al., 2019 \& Listos et al., 2019), and exploring the alternative medicine of morphine (Suliman et al., 2016).

Researches were designed following various models; in vivo (Halim et al., 2017; Vashchinkina et al., 2018), in vitro (Suliman et al., 2016), and ex vivo (Jeon et al., 2019). Listos et al. (2019) had

* To whom correspondence should be addressed. reviewed four different experiments depend on the addiction phases; morphine dependence, withdrawal, tolerance, and induced behavioral sensitization. Out of these four phases, morphine-induced behavioral sensitization is done via in vivo model since it measures morphine-seeking behavior such as locomotor activity and rewarding behavior. Morphine dependence, withdrawal, and tolerance can be designed using in vitro model to measure the protein markers affected. Thus, a suitable and reliable in vitro model must be established.

American Type Culture Collection (ATCC, USA) is currently supplying more than ten different human neuroblastoma cell lines. Out of that number, the current researchers have frequently use the SK-NSH cell line (Paschou et al., 2020; Sánchez-Blázquez et al., 2020). The present study was designed to establish the SK-N-SH as an addiction model to observe the mechanism of alternative medicine in treating morphine addiction. With the same model, 
the present study was conducted by using methadone as a positive control to help further explanation of morphine and methadone mechanism interrelatedly.

\section{MATERIALS AND METHODS}

\section{Materials}

Human neuroblastoma cells line SK-N-SH (ATCC ${ }^{\circledR}$ HTB-11 ${ }^{\mathrm{TM}}$, American Type Culture Collection, ATCC, USA); Minimum Essential Medium (MEM), fetal bovine serum (FBS), penicillinstreptomycin, Trypsin, phosphate-buffered saline (PBS) solutions (Gibco Life Technologies, Invitrogen, USA); dimethyl sulfoxides (DMSO), retinoic acid (RA), forskolin (Sigma-Aldrich, USA); morphine sulphate pentahydrate (M-35-SU), d,I-Methadone. $\mathrm{HCl}$ (MET-637) (Lipomed AG, Switzerland); isobutylmethylxanthine (IBMX), radioimmunoprecipitation assay (RIPA) buffer, protease inhibitor (Amresco, USA); $\alpha$-synuclein, vesicle-associated membrane protein 2 (VAMP2), $\beta$-arrestin $1 / 2$, mitogen-activated protein/ERK 1/2 (MEK1/2), anti- $\beta$-actin, and horse-radish peroxidase (HRP) (Cell Signalling Technology, Massachusetts); WesternBright $^{\mathrm{TM}}$ ECL, WesternBright ${ }^{\mathrm{TM}}$ Peroxide (Advansta, USA).

\section{Cell culture and neuronal induction}

The human neuroblastoma cell line SK-N-SH (ATCC ${ }^{\circledR}$ HTB-11 ${ }^{\mathrm{TM}}$ ) was cultured and maintained following prescription by American Type Culture Collection (ATCC). The cell was introduced to $10 \mu \mathrm{M}$ of retinoic acid (RA) for six days (Suliman et al., 2016).

\section{Morphine and methadone treatments}

The method for chronic morphine was following the study by Jamil et al. (2013). The cells were introduced to $50 \mu \mathrm{M}$ of morphine sulphate pentahydrate for $24 \mathrm{hr}$ and subsequently followed by $1 \%$ of DMSO or $50 \mu \mathrm{M}$ of d,I-Methadone for another $24 \mathrm{hr}$.

\section{Receptor affinity}

Three types of opioid receptors were examined using $10 \mu \mathrm{M}$ of the following antagonist; $\beta$ funaltrexamine hydrochloride ( $\mu$-opioid receptor), nor-binaltrophimine dihydrochloride ( $\kappa$-opioid receptor), and natrindole hydrochloride ( $\delta$-opioid receptor) (Greenwood \& Dragunow, 2010). To investigate the type of receptor involved in chronic morphine in SK-N-SH, two different experiments were studied; pre-treatment of antagonists before chronic morphine and post-treatment of antagonists before methadone. For pre-treatment of the antagonist, the SK-N-SH cell was treated with $10 \mu \mathrm{M}$ of antagonists were for $60 \mathrm{~min}$, followed by $24 \mathrm{hr}$ of $50 \mu \mathrm{M}$ of morphine sulphate pentahydrate. For post-treatment of the antagonist, the cell was induced with $24 \mathrm{hr}$ of $50 \mu \mathrm{M}$ of morphine sulphate pentahydrate, followed by $60 \mathrm{~min}$ of $10 \mu \mathrm{M}$ of antagonists and subsequently by $50 \mu \mathrm{M}$ of d,I-Methadone. $\mathrm{HCl}$ for another $24 \mathrm{hr}$. The cytosolic fraction of the cell was used to run the cAMP assay (cAMP Direct Immunoassay Kit, Calbiochem, Germany).

\section{Protein expression}

Withdrawal properties, endocytic machinery, desensitization or internalization, and cellular adaptation were observed through the expression of protein marker by western blot technique; $\alpha$ synuclein, VAMP2, $\beta$-arrestin 1/2, MEK $1 / 2$ (Suliman et al., 2016). For the electrophoresis procedure, $4 \%$ of stacking gel and $10 \%$ of resolving gel were used, run at $100 \mathrm{~V}$ for $60 \mathrm{~min}$, followed by $150 \mathrm{~V}$ for another $30 \mathrm{~min}$. The concentration of antibodies used is $1: 1000$.

\section{Statistical analysis}

The data collected were analyzed using IBM SPSS Statistics 21 for one-way ANOVA and Tukey’s multiple comparison test.

\section{RESULTS}

Pre-treatment of the antagonist was done to evaluate the involvement of the receptor in chronic morphine incubation. Figure 1 shows the changes in the concentration of cAMP before chronic morphine exposure to the cell. Data showed that upon blocking the $\mu$-opioid receptor, the expression of cAMP in chronic morphine-induced cells was comparable to control. In contrast, by blocking of ê- and ä-opioid receptors, there were significant changes in cAMP concentration.

Post-treatment of an antagonist after the chronic morphine-induced cell was expressed in Figure 2. From the figure, blockage of the $\mu$-opioid receptor was observed to diminish the effect of methadone. compared to $\delta$ - and $\kappa$-opioid receptors, blockage of those receptors was observed to resume the effect of methadone to normalize the cAMP level influenced by chronic morphine treatment.

Specific markers were used to analyze the withdrawal activity, endocytic machinery, desensitization, or internalization of receptor and cellular adaptation. The proteins expression of $\alpha$-synuclein, VAMP2, $\beta$-arrestin 1/2, and MEK $1 / 2$ were observed to be altered in the chronic morphine-induced cell (Figure 3 ). The treatment of methadone had normalized the changes by morphine, comparable to control. 


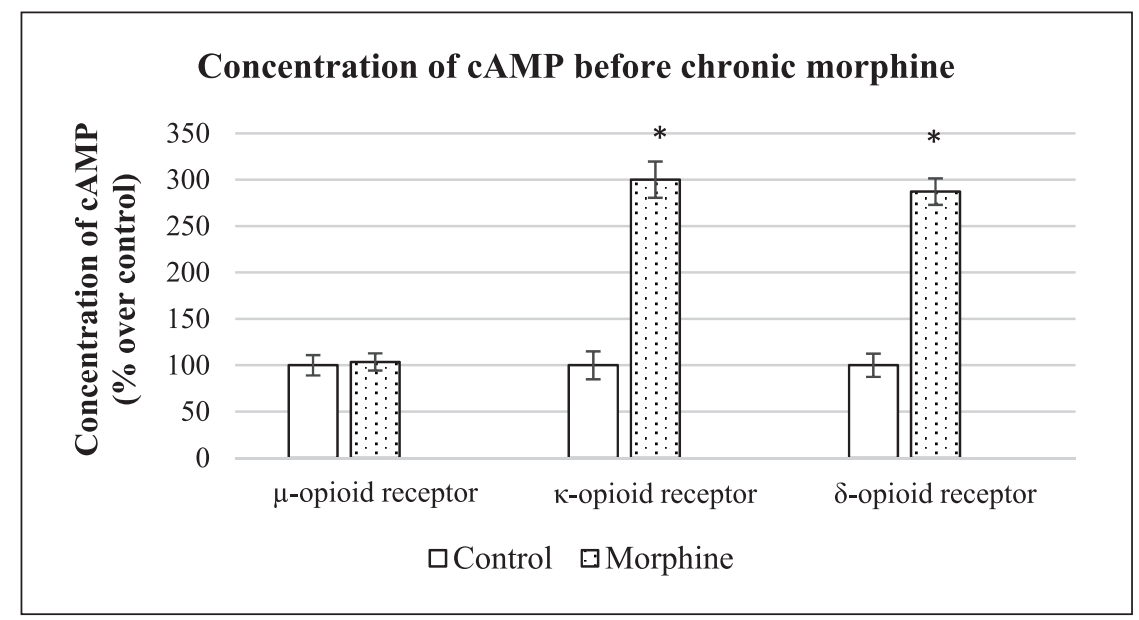

Fig. 1. The concentration of cAMP after antagonist treatment. The bar chart expressed the concentration of cAMP in percentage over control. $* P<0.05$ as compared to control.

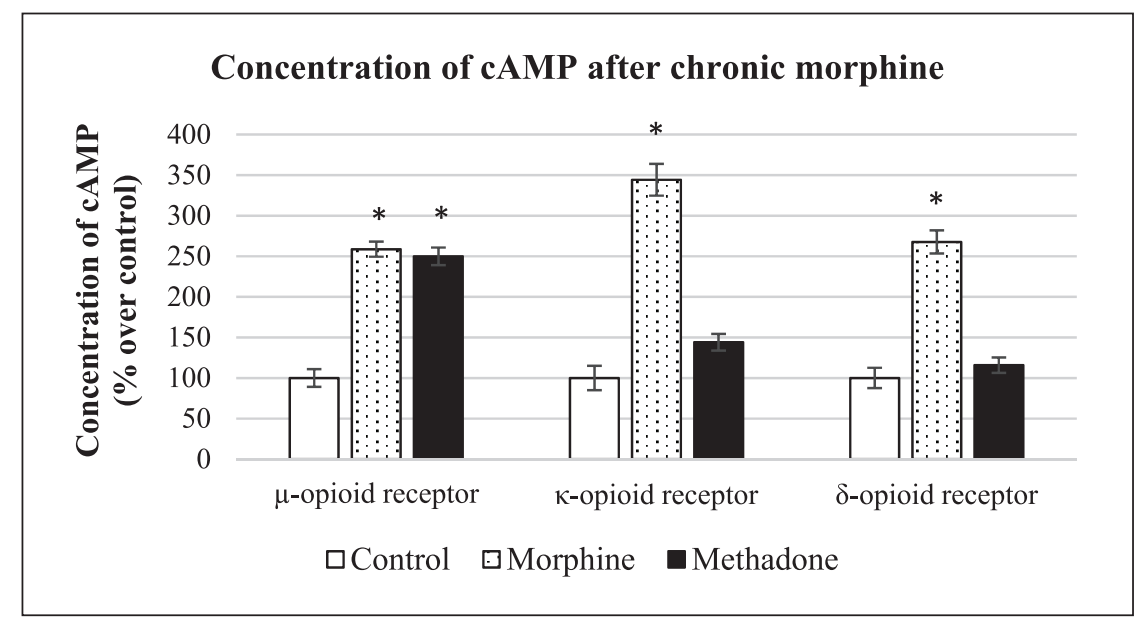

Fig. 2. The concentration of cAMP after antagonist treatment. The bar chart expressed the concentration of cAMP in percentage over control. ${ }^{*} P<0.05$ as compared to control.

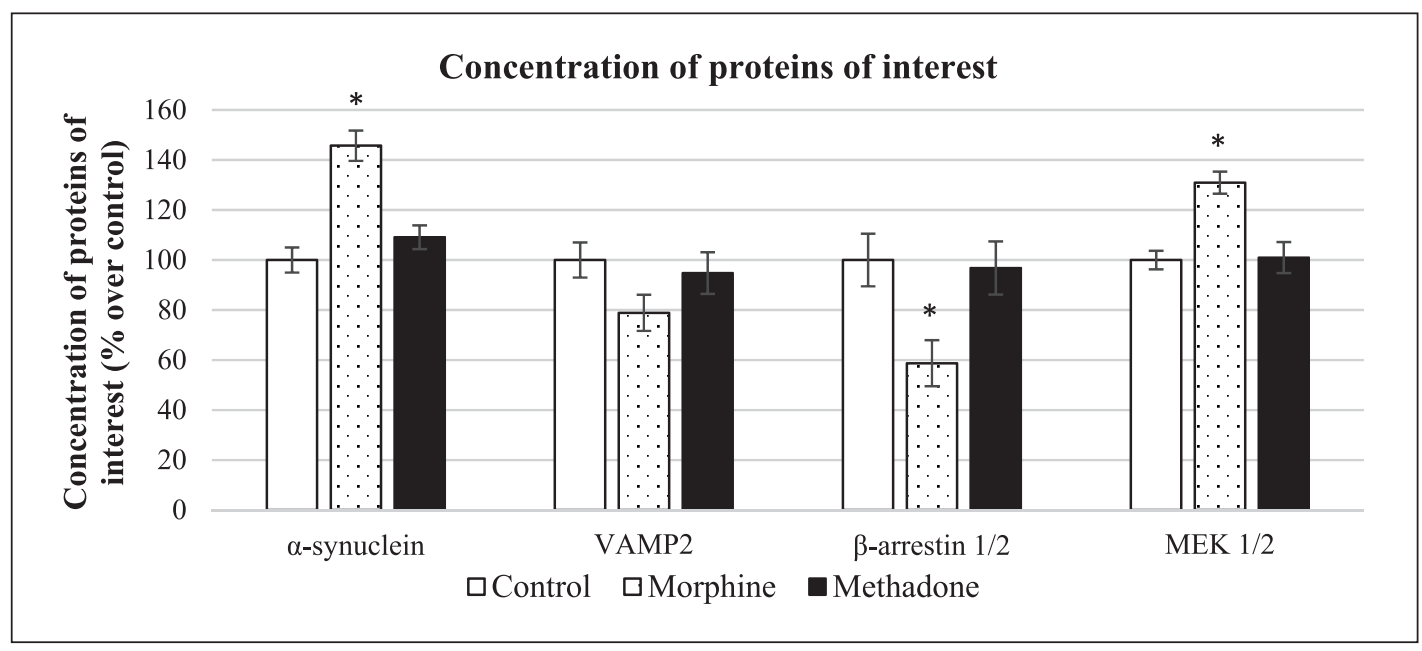

Fig. 3. The concentration of protein of interest upon chronic morphine. The bar chart shows the expression of $\alpha$-synuclein, VAMP2, $\beta$-arrestin $1 / 2$, and MEK $1 / 2$. The data were expressed in percentage over control. $* P<0.05$ as compared to control and methadone. 


\section{DISCUSSION}

The human neuroblastoma cell line, SK-N-SH, was used throughout the study. SK-N-SH purchased from ATCC is a cell derived from a girl suffering from neuroblastoma disease ("SK-N-SH ATCC ® HTB$11^{\mathrm{TM}}$ Homo sapiens brain; derived from meta", 2016). The cell line was hypothesized to express a muscarinic (Olianas et al., 2016) and opioid receptors (Caputi et al., 2018). Researches had postulated the involvement of opioids (Grim et al., 2020) in expressing morphine addiction. Referring to Grim (2020), three types of opioids were used to determine the type of opioid receptor involved in morphine withdrawal in SK-N-SH.

To observe the receptor involved in morphine and methadone, two different experiments were studied. The blockage of the $\mu$-opioid receptor of the SK-N-SH cell before the chronic morphine treatment has diminished the effect of morphine, as showed in Figure 1. The cAMP level of the $\mu$-opioid antagonist was comparable between the control and morphine, hypothesized the effects of morphine was denied by the blockage of the $\mu$-opioid receptor. In contrast, the blockage of $\kappa$ - and $\delta$-opioid receptors were observed to resume the effects of morphine by increasing the level of cAMP in the cell, postulating the involvement of $\mu$-opioid receptor in expressing the effects of morphine in SK-N-SH cell line.

Observing the involvement of $\mu$-opioid receptors in morphine addiction is fruitless without proposing the treatment for the addiction. Methadone, a synthetic opioid, was manufactured to manage an opioid addiction patient (Nurulhuda et al., 2018; Noble \& Marie, 2019). To study the effect of methadone in the addiction-induced cell, antagonists were introduced to the addicted cell before being treated with methadone. By blocking the $\delta$ - and $\kappa$ opioid receptors, the treatment of chronic morphine expressing the addiction property by increased concentration of cAMP. Increased cAMP expression in SK-N-SH was postulated to demonstrate the addiction activity (Jamil et al., 2013). The same cell that was subsequently treated with methadone was observed to reduce the concentration of cAMP as it was comparable to control, suggesting the blockage of $\delta$ - and $\kappa$-opioid receptors did not influence the effect of methadone to the addicted cell line. In contrast, addicted SK-N-SH treated with $\mu$-opioid antagonist followed by subsequence treatment of methadone diminished the effect of methadone. The level of cAMP after treatment of methadone was significantly differenced as compared to control. The data showed that morphine bound to the $\mu$-opioid receptor to express the addiction properties while methadone reacted on the same receptor to diminish the effect of morphine comparable to control.
The level of cAMP in demonstrating the activity of addiction in SK-N-SH was widely reported (Jamil et al., 2013; Yuan et al., 2020). Following the study on the receptor, indirectly shows the addiction activity in SK-N-SH upon chronic treatment of morphine. To justify the addiction property expressed by SK-N-SH, an additional protein marker was evaluated, $\alpha$-synuclein. Up-regulated $\alpha$-synuclein was proclaimed to express morphine addiction (Ujcikova et al., 2020). To observe the properties of morphine withdrawal in SK-N-SH, the cytosolic fraction of the morphine-induced cell was collected and proceeded to determine the concentration of $\alpha$-synuclein. As showed in Figure 3, the chronic morphine-induced cell showed increased level $\alpha$-synuclein expression, exhibited the addiction property. The treatment of methadone on the addicted cells was observed to down-regulate the concentration of $\alpha$-synuclein, as it was proclaimed to express withdrawal activity (Ujcikova et al., 2020).

As reported, $\alpha$-synuclein plays a major role in synaptic plasticity (Valdinocci et al., 2017). $\alpha$ synuclein was observed to alter the dopaminergic system in the brain, leads to exhibiting dependence and withdrawal behaviors (Ziolkowska et al., 2005). Alteration in the dopaminergic system affects various mechanisms including the endocytic machinery (Ziolkowska et al., 2005; Fauzi et al., 2018). Though the increased level of $\alpha$-synuclein in the SK-N-SH cell line was proclaimed to demonstrate the property of morphine addiction, it was also representing the reduced endocytic machinery activity. As to justify the proclaim, VAMP2 was observed. VAMP2 or synaptobrevin is a vesicular soluble $\mathrm{N}$ ethylmaleimide-sensitive factor activating protein receptor (v-SNARE) (Lou et al., 2017). Downregulation of v-SNARE was hypothesized to inhibit the release of neurotransmitters in the treatment of (Lai et al., 2014 VAMP2 was postulated to bind to syntaxin and SNAP-25 to aid the vesicle trafficking at the presynaptic terminal of the neuron (Xu et al., 2004). As showed in Figure 3, SK-N-SH cells treated with chronic morphine expressed a non-significant low concentration of VAMP2 as compared to control. It suggested that chronic morphine caused the reduction in exocytosis of the neurotransmitter, thus diminishes the vesicle release. By the treatment of methadone, it was observed to normalize the concentration of VAMP2, comparable to control.

Activation of the $\mu$-opioid receptor by effectors mainly inhibits the adenylyl cyclase (Koehl et al., 2018). However, upon activation by morphine will activate the adenylyl cyclase and subsequently increases the level of cAMP (Jamil et al., 2013). Administration of morphine was postulated to induced desensitization of the $\mu$-opioid receptor (Ma et al., 2020), making the activated receptor to 
endocytosed and became inactive (Ma et al., 2020). Physiologically, the desensitization of the receptor prevents the overstimulation of the receptor by the effector. However, these physiological changes also limit therapeutic usage against the effectors (Ferguson, 2001).

The desensitization or internalization of the $\mu$-opioid receptor was observed via the involvement of $\beta$-arrestin (Koshimizu et al., 2018). The binding of $\beta$-arrestin $1 / 2$ to clathrin was suggested to initiate the internalization of receptors (Goodman et al., 1996). Figure 3 showed the down-regulation of $\beta$-arrestin $1 / 2$ proclaimed to demonstrate the desensitization of the $\mu$-opioid receptor. With the treatment of methadone, the addicted SK-N-SH cells have expressed an internalization of the $\mu$-opioid receptor, observed by increased concentration of $\beta$-arrestin $1 / 2$. Physiologically, chronic morphine was unable to cause the overstimulation of proteins since there was desensitization of the $\mu$-opioid receptor. However, the effects of chronic morphine were persisted showed by increased cAMP and $\alpha$-synuclein and decreased VAMP2.

The increased protein markers involved in expressing the withdrawal activity, endocytic machinery, and desensitization or internalization properties were influenced by cellular adaptation before chronic treatment of morphine (Zhang et al., 2020). Narita (2001) suggested that desensitization and internalization processes are the characteristics of cellular adaptation. In the human brain, the MEKERK signaling pathway is stimulated by morphine expressing morphine addiction activities (Zhang et al., 2020). MEK is an essential protein marker for opioid addiction (Lin et al., 2010). A high level of MEK upon chronic morphine was postulated to demonstrate morphine dependence, tolerance, and withdrawal, consistent with the report by Al-Hasani and Bruchas (2011).

\section{CONCLUSION}

As observed through the study, chronic morphine treatment on SK-N-SH react on the $\mu$-opioid receptor. The addiction properties expressed by the upregulation of withdrawal markers; $\alpha$-synuclein and cAMP, postulates the involvement of stimulated adenylyl cyclase pathways by morphine. Increased $\alpha$-synuclein and decreased VAMP2 are related to decreased endocytic machinery, suggested to reduce the release of neurotransmitters in the presynaptic terminal of a neuron. The desensitization of $\mu$-opioid receptor in SK-N-SH by morphine was expressed by decreased $\beta$-arrestin $1 / 2$ thus supposedly preventing the overstimulation of effects by the morphine. However, cellular adaptation was hypothesized to happen so that the effects of morphine were consistently stimulated.

\section{ACKNOWLEDGEMENTS}

This study was funded by the Ministry of Science, Technology and Innovation (MOSTI), Malaysia (Grant no: ScienceFund, 06-01-04-SF1673; Putra Grant RUGS, GP-IPS/2014/9432600, and FRGS, 02-01-151686FR). The authors are grateful to all staff of the Laboratory of Anatomy and Histology and Forest Research Institute of Malaysia for all the help and guide. Thanks to the Department of Biomedical Science and Medical Genetic Laboratory for the Gel Documentation equipment.

\section{REFERENCES}

Ahmad, N.Z., Mat, K.C., Mohamad, N., Husain, R.B., Bakar, N.H.A., Zakaria, N.H. \& Shariff, M.H.M. 2019. A review on opioid dependence, mechanism and treatments used: option of treatments: modern versus alternative medicine. Bangladesh Journal of Medical Science, 18(2): 171-177.

Al-Hasani, R. \& Bruchas, M.R. 2011. Molecular mechanisms of opioid receptor-dependent signaling and behavior. Journal of the American Society of Anesthesiologists, 115(6): 1363-1381.

Caputi, F.F., Acquas, E., Kasture, S., Ruiu, S., Candeletti, S. \& Romualdi, P. 2018. The standardized Withania somnifera Dunal root extract alters basal and morphine-induced opioid receptor gene expression changes in neuroblastoma cells. BMC Complementary and Alternative Medicine, 18(1): 9.

Dürsteler MacFarland, K.M., Brugger, I., Bönsch, D., Schmid, O., Kornhuber, J., Bleich, S. \& Wiesbeck, G.A. 2012. Alpha synuclein and heroin craving in opiate dependent patients on injectable heroin maintenance. Addiction Biology, 17(5): 875-886.

Fauzi, N.F.A.M., Bakar, N.H.A., Mohamad, N., Hadzrullathfi, S., Omar, S., Ismail, M.Z. \& Mustafa, N.S. 2018. Nigella sativa effects on neurotransmitter systems: potential treatment for drug tolerance and dependence. International Journal of Pharmaceutical Research and Allied Sciences, 7(1): 196-200.

Ferguson, S.S. 2001. Evolving concepts in G protein-coupled receptor endocytosis: the role in receptor desensitization and signaling. Pharmacological Reviews, 53(1): 1-24. 
Goodman, O.B., Krupnick, J.G., Santini, F., Gurevich, V.V., Penn, R.B., Gagnon, A.W., et al. 1996. $\beta$-Arrestin acts as a clathrin adaptor in endocytosis of the $\beta 2$-adrenergic receptor. Nature, 383(6599): 447-450.

Greenwood, J.M. \& Dragunow, M. 2010. M3 muscarinic receptors promote cell survival through activation of the extracellular regulated kinase (ERK1/2) pathway. European Journal of Pharmacology, 640(1): 38-45.

Grim, T.W., Schmid, C.L., Stahl, E.L., Pantouli, F., Ho, J.H., Acevedo-Canabal, A. \& Bohn, L.M. 2020. AG protein signaling-biased agonist at the $\mu$-opioid receptor reverses morphine tolerance while preventing morphine withdrawal. Neuropsychopharmacology, 45(2): 416-425.

Halim, S., Mohamad, N., Bakar, N.H.A., Omar, S.H.S., Othman, M.S., Thoarlim, A. \& Zakaria, N.H. 2017. Effect of zamzam water alone or in combination with methadone on animal withdrawal symptoms in morphine dependent rats. Research Journal of Pharmacy and Technology, 10(11): 3783-3788.

Hassan, R., See, C.P., Sreenivasan, S., Mansor, S.M., Müller, C.P. \& Hassan, Z. 2020. Mitragynine attenuates morphine withdrawal effects in rats - a comparison with methadone and buprenorphine. Frontiers in Psychiatry, 11.

Jamil, M.F.A., Subki, M.F.M., Lan, T.M., Majid, M.I.A. \& Adenan, M.I. 2013. The effect of mitragynine on cAMP formation and mRNA expression of mu-opioid receptors mediated by chronic morphine treatment in SK-N-SH neuroblastoma cell. Journal of Ethnopharmacology, 148(1): 135-143.

Jeon, S.Y., Kim, Y.H., Kim, S.J., Suh, S.K. \& Cha, H.J. 2019. Abuse potential of 2-(4-iodo-2, 5-dimethoxyphenyl) N-(2-methoxybenzyl) ethanamine (25INBOMe); in vivo and ex vivo approaches. Neurochemistry International, 125 : 74-81.

Koehl, A., Hu, H., Maeda, S., Zhang, Y., Qu, Q., Paggi, J.M. \& Schertler, G.F. 2018. Structure of the $\mu$-opioid receptor-G i protein complex. Nature, 558(7711): 547-552.

Koshimizu, T.A., Honda, K., Nagaoka-Uozumi, S., Ichimura, A., Kimura, I., Nakaya, M. \& Hirasawa, A. 2018. Complex formation between the vasopressin $1 \mathrm{~b}$ receptor, $\beta$-arrestin-2, and the $\mu$-opioid receptor underlies morphine tolerance. Nature Neuroscience, 21(6): 820-833.

Lai, Y., Kim, S., Varkey, J., Lou, X., Song, J.K., Diao, J. \& Shin, Y.K. 2014. Nonaggregated $\alpha$-synuclein influences SNARE-dependent vesicle docking via membrane binding. Biochemistry, 53(24): 3889-3896.
Lin, X., Wang, Q., Ji, J., Yu, L.C. 2010. Role of MEK ERK pathway in morphine induced conditioned place preference in ventral tegmental area of rats. Journal of Neuroscience Research, 88(7): 1595 1604.

Listos, J., Łupina, M., Talarek, S., Mazur, A., OrzelskaGórka, J. \& Kotliñska, J. 2019. The mechanisms involved in morphine addiction: an overview. International Journal of Molecular Sciences, 20(17): 4302.

Lou, X., Kim, J., Hawk, B.J. \& Shin, Y.K. 2017. $\alpha$-Synuclein may cross-bridge v-SNARE and acidic phospholipids to facilitate SNAREdependent vesicle docking. Biochemical Journal, 474(12): 2039-2049.

Ma, X., Chen, R., Huang, M., Wang, W., Luo, L., Kim, D.K. \& Xu, T. 2020. DAMGO-induced $\mu$ opioid receptor internalization and recycling restore morphine sensitivity in tolerant rat. European Journal of Pharmacology, 878:173118.

Narita, M., Funada, M. \& Suzuki, T. 2001. Regulations of opioid dependence by opioid receptor types. Pharmacology and Therapeutics, 89(1): 1-15.

Noble, F. \& Marie, N. 2019. Management of opioid addiction with opioid substitution treatments: beyond methadone and buprenorphine. Frontiers in Psychiatry, 9: 742.

Nurulhuda, M., Khairi, C.M. \& Norwati, D. 2018. Is needle exchange programme still relevant in the advent of methadone maintanence therapy?, in: 3rd AMDI International Biohealth Sciences Conferences. Malaysia.

Olianas, M.C. Dedoni, S. \& Onali, P. 2016. Protection from interferon $\beta$ induced neuronal apoptosis through stimulation of muscarinic acetylcholine receptors coupled to ERK1/2 activation. British Journal of Pharmacology, 173(19): 2910-2928.

Paschou, M., Maier, L., Papazafiri, P., Selescu, T., Dedos, S.G., Babes, A. \& Doxakis, E. 2020. Neuronal microRNAs modulate TREK twopore domain $\mathrm{K}^{+}$channel expression and current density. RNA biology, 17(5): 651-662.

Sánchez-Blázquez, P., Cortés-Montero, E., RodríguezMuñoz, M., Merlos, M. \& Garzón-Niño, J. 2020. The Sigma 2 receptor promotes and the Sigma 1 receptor inhibits mu-opioid receptor-mediated antinociception. Molecular Brain, 13(1): 1-9.

SK-N-SH ATCC ® HTB-11 ${ }^{\text {TM }}$ Homo sapiens brain; derived from meta. 2016. Atcc.org. URL https: //www.atcc.org/products/all/HTB-11.aspx\# generalinformation (accessed 9.8.16).

Suliman, N.A., Mohd Moklas, M.A., Mat Taib, C.N., Adenan, M.I., Hidayat Baharuldin, M.T., Basir, R. \& Amom, Z. 2016. Morphine antidependence of Erythroxylum cuneatum (Miq.) Kurz in neurotransmission processes in vitro. EvidenceBased Complement Alternative Medicine, 1-9. 
Ujcikova, H., Cechova, K., Jagr, M., Roubalova, L., Vosahlikova, M. \& Svoboda, P. 2020. Proteomic analysis of protein composition of rat hippocampus exposed to morphine for 10 days; comparison with animals after 20 days of morphine withdrawal. PLoS ONE, 15(4): e0231721.

Valdinocci, D., Radford, R.A., Siow, S.M., Chung, R.S. \& Pountney, D.L. 2017. Potential modes of intercellular $\alpha$-synuclein transmission. International Journal of Molecular Sciences, 18(2): 469.

Vashchinkina, E., Piippo, O., Vekovischeva, O., Krupitsky, E., Ilyuk, R., Neznanov, N. \& Korpi, E.R. 2018. Addiction related interactions of pregabalin with morphine in mice and humans: reinforcing and inhibiting effects. Addiction Biology, 23(3): 945-958.

Xu, N.J., Yu, Y.X., Zhu, J.M., Liu, H., Shen, L., Zeng, R., Zhang, X. \& Pei, G. 2004. Inhibition of SNAP-25 phosphorylation at Ser187 is involved in chronic morphine-induced down-regulation of SNARE complex formation. Journal of Biological Chemistry, 279(39): 40601-40608.
Yadlapalli, J.S.K., Dogra, N., Walbaum, A.W., Wessinger, W.D., Prather, P.L., Crooks, P.A. \& Dobretsov, M. 2017. Evaluation of analgesia, tolerance and the mechanism of action of morphine-6-O-sulfate across multiple pain modalities in Sprague-Dawley rats. Anesthesia and Analgesia, 125(3): 1021.

Yuan, L., Luo, L., Ma, X., Wang, W., Yu, K., Shi, H. \& Xu, T. 2020. Chronic morphine induces cyclic adenosine monophosphate formation and hyperpolarization-activated cyclic nucleotidegated channel expression in the spinal cord of mice. Neuropharmacology, 108222.

Zhang, H., Wang, Q., Sun, Q., Qin, F., Nie, D., Li, Q. \& Lu, Z. 2020. Effects of compound 511 on BDNF-TrkB Signaling in the mice ventral tegmental area in morphine-induced conditioned place preference. Cellular and Molecular Neurobiology, 1-15.

Ziolkowska, B., Gieryk, A., Bilecki, W., WawrzczakBargiela, A., Wedzony, K., Chocyk, A. \& Przewlocki, R. 2005. Regulation of $\alpha$-synuclein expression in limbic and motor brain regions of morphine-treated mice. Journal of Neuroscience, 25(20): 4996-5003. 
